\title{
Experiências de famílias com usuários atendidos em dispositivos de atenção psicossocial
}

I ${ }^{1}$ Marcia Maria Mont'Alverne de Barros, ${ }^{2}$ Maria Salete Bessa Jorge,

${ }^{3}$ Mardênia Gomes Ferreira Vasconcelos I

Resumo: Pesquisa de natureza qualitativa, realizada no Nordeste brasileiro, de setembro a novembro de 2012, em que se objetivou compreender experiências de famílias com usuários atendidos em dispositivos de atenção psicossocial. Utilizaramse, para a coleta das informações, a entrevista semiestruturada, o grupo focal e a observação participante. Como participantes da pesquisa, incluíram-se vinte famílias cuidadoras de usuários adultos com transtornos mentais graves, com histórico de atendimento em extinto hospital psiquiátrico e em tratamento, na ocasiāo do estudo, em dispositivo de atenção psicossocial. $\mathrm{Na}$ análise do material empírico, utilizou-se a fenomenologia hermenêutica de Ricoeur. As famílias enfrentavam dificuldades no cuidado em domicílio, destacandose a situação de vigilância de comportamentos problemáticos de familiares com transtornos mentais. Havia satisfação das famílias concernente à atenção prestada pelo dispositivo; entretanto, elas evidenciaram a necessidade de melhorias neste, mediante inserção delas no cuidado em saúde mental, qualificação do acolhimento operado nesse serviço, regularização da escassez de medicamentos e garantia de transporte para familiares com transtornos mentais assistidos.

> Palavras-chave: famílias; experiências; reforma psiquiátrica.

\author{
1 Doutora em Saúde Coletiva, \\ Associação Ampla (UECE/ \\ UFC/Unifor); professora do \\ Departamento de Terapia \\ Ocupacional da Universidade \\ Federal da Paraíba (UFPB), \\ Brasil. Endereço eletrônico: \\ marcia_mab@hotmail.com \\ 2 Pós-doutora em Saúde \\ Coletiva pela UNICAMP; \\ professora titular da \\ Universidade Estadual do \\ Ceará (UECE), Fortaleza, Brasil. \\ Pesquisadora CNPq. Endereço \\ eletrônico: maria.salete.jorge@ \\ gmail.com \\ ${ }^{3}$ Doutoranda em Saúde \\ Coletiva, Associação \\ Ampla (UECE/UFC/Unifor) \\ Universidade Estadual do Ceara, \\ Fortalexza, Brasil. Endereço \\ eletrônico: mardeniagomes@ \\ yahoo.com.br
}

Recebido em: 16/12/2012 Aprovado em: 13/08/2013 
No período que antecedeu o processo de reforma psiquiátrica, a pessoa com transtorno mental era apartada da família, considerando-se as vertentes do "isolamento terapêutico" para "restituição da liberdade subtraída pela alienação". Esta, por sua vez, era considerada uma desarmonia na mente, no âmbito das paixões que impossibilitavam ao indivíduo perceber a realidade de forma objetiva (AMARANTE, 2007, p. 29). Por isso, a pessoa com transtorno mental era encarada como perigosa para a estrutura familiar, podendo subverter os membros da família considerados mais frágeis, tornando-se um modelo exemplar negativo ao ser imitado. Entretanto, apesar da suposta necessidade de proteger a família do seu membro doente, esta era também indiciada como promotora da loucura. Essa contradição se dava devido à ideia de que a alienação era oriunda da estrutura familiar e dos conflitos gerados a partir dessa relação (PIMENTA; ROMAGNOLI, 2008).

Por ser considerada agente patogênico, a família também era afastada da pessoa com transtorno mental e colocada em segundo plano. Devido à existência de promessas de cura para o adoecimento mental, seu papel era de passividade. Cabia à família esperar pelos resultados das intervenções realizadas pelos detentores do saber competente. No interior dos hospitais psiquiátricos, a família funcionava como informante da enfermidade e da trajetória da pessoa com transtorno mental. $\mathrm{O}$ cuidado, nesse cenário, era de responsabilidade exclusiva dos trabalhadores da saúde mental e dos serviços assistenciais (ROSA, 2005).

A história evidencia que a família foi mantida afastada do tratamento da pessoa com transtorno mental porque esta, na maioria das vezes, encontrava-se em hospitais psiquiátricos. Nesse modelo, o familiar era alijado do tratamento, e a proibição das visitas nas primeiras semanas de internação acabava também reforçando a culpa da família (NAVARINI; HIRDES, 2008).

As rupturas com essas vertentes do alienismo e da psiquiatria ganharam evidência a partir de 1970, com a experiência original de transformação radical do hospital psiquiátrico, em Trieste, na Itália, que inspirou a reforma psiquiátrica brasileira, já nos anos 80 . Esse processo fomentou transformações no modelo assistencial em saúde mental, com destaque para a participação da família de forma ativa, numa nova maneira de conceber e tratar as pessoas com transtornos mentais (MORENO, 2009). Na conjuntura da reforma psiquiátrica, a família 
passou a ser estimulada a desempenhar novo papel, uma vez que, no modelo tradicional, era alvo de desautorização, em virtude de projeto que não vislumbrava suporte terapêutico às famílias para lidarem com a condição do adoecimento e suas implicações nos universos familiar e social (SILVA; DALMOLIN, 2010).

A atual política de saúde mental adotada no Brasil possibilita a aproximação das famílias aos seus membros com transtornos mentais. Isso porque preconiza a efetivação da reforma psiquiátrica, por meio da promoção de relações entre trabalhadores, usuários e familiares pautadas no acolhimento, no vínculo, na adoção de modelo de saúde humanizado que considere o cuidado integral e ativa participação de todos e na elaboração e condução dos projetos terapêuticos, fortalecendo o "protagonismo social", no sentido de desenvolver autonomia e autodeterminação (BRASIL, 2010).

Há necessidade de criação de políticas intersetoriais e de potencialização de ações que garantam atendimento, capacitação, informação e suporte às famílias e aos cuidadores das pessoas com transtornos mentais, mediante o envolvimento de todos os atores no processo terapêutico, bem como acolhimento na rede de serviços de saúde mental. Outro aspecto importante é a criação de programas de incentivo a projetos e iniciativas que privilegiem o trabalho com a família, no sentido de estimular o fortalecimento do vínculo doméstico (BRASIL, 2010).

Esse novo cenário revelou importantes desafios para as famílias e os trabalhadores da saúde que cuidam de pessoas com transtornos mentais, especialmente no que diz respeito às repercussões de diferentes naturezas no âmbito da família, tais como redimensionamento permanente dos cotidianos, tensōes no convívio e sobrecarga para o cuidador familiar.

No tocante aos problemas enfrentados pela convivência da família com a pessoa com transtorno mental, os estudos de Koga (1997), Pergoraro e Caldana (2008), Dimenstein et al. (2010), Nóbrega e Coriolano (2011), dentre outros, demonstraram dificuldades enfrentadas pelas famílias junto às novas propostas de cuidados, que interferem diretamente nas dinâmicas familiares e na conjuntura de corresponsabilização, contemplada pelo modelo de atenção psicossocial.

O objeto deste estudo mostra-se relevante e original, particularmente pelo fato de a inserção da família estar preconizada no cerne da Política Nacional de Saúde Mental. No entanto, ainda evidenciam-se, na prática, dificuldades de inclusão dos familiares no projeto terapêutico dos usuários dos serviços substitutivos 

insatisfatória no seu modo de auxiliar as famílias no enfrentamento da doença mental (DIMENSTEIN et al., 2010).

Tais evidências são importantes desafios para os trabalhadores da saúde na realização de um trabalho compartilhado com as famílias, no sentido de que estas sejam, de fato, inseridas no cuidado. Uma maior aproximação dessas famílias, por meio da compreensão de suas experiências, poderá representar a potência de operar mudanças concretas em seu cotidiano e no de pessoas com transtornos mentais, vislumbrando-se a ampliação das possibilidades de resolutividade nos dispositivos compromissados com a efetivação da reforma psiquiátrica, evitandose o enveredamento para tentativas de reedições de institucionalização.

Nesse prisma, o artigo objetivou compreender as experiências das famílias com usuários atendidos nos dispositivos de atenção psicossocial.

\section{Método}

Optou-se por uma pesquisa com abordagem qualitativa, numa perspectiva de compreensão das experiências de cuidado no campo da saúde mental e atenção psicossocial. Ainda é possível, por meio dessa opção, dimensionar a compreensão dos significados, sentidos, intencionalidades e questôes subjetivas inerentes aos atos, atitudes, relações e estruturas sociais; conforme sinaliza Minayo (2008, p. 21), “[...] o universo de significados, motivos, aspiraçôes, crenças, valores e atitudes, o que corresponde a um espaço mais profundo das relações, [...] que não podem ser reduzidos à operacionalização de variáveis".

A investigação teve como cenário a Rede de Atenção Integral à Saúde Mental (RAISM), composta por serviços como Centro de Atenção Psicossocial, na modalidade geral tipo II (CAPS II) e Centro de Atenção Psicossocial em referência para álcool e drogas (CAPS AD), unidade de internação de psiquiatria em hospital geral, serviço residencial terapêutico e ambulatório de psiquiatria, que buscam articular-se com os centros de saúde da família. Esta Esses serviços estão localizados num município do interior do Ceará, com 190.724 habitantes (IBGE, 2011) e cobertura assistencial da Estratégia Saúde da Família (ESF) de 93,4\% da população.

A rede foi implantada em substituição ao modelo hospitalocêntrico manicomial vigente no município por 26 anos. Há treze anos o local vem passando por um 
processo de superação desse modelo e de implantação do processo de reforma psiquiátrica. Desse modo, urge a necessidade de compreender as experiências vivenciadas na atualidade pelas famílias com usuários atendidos nos dispositivos de atenção psicossocial.

Participaram da pesquisa vinte famílias, representadas pelos membros cuidadores das pessoas com transtorno mental atendidas no CAPS II, selecionados por desempenharem o papel de cuidadores dos familiares com transtornos mentais há, pelo menos, dois anos e terem condições psíquicas para participar da investigação.

As famílias foram definidas pela relevância das informaçōes e observações que indicaram contribuições significantes e adequadas ao delineamento do objeto em apreensão. $\mathrm{O}$ processo adotado pautou-se no aprofundamento das questôes levantadas e dos objetivos preconizados, com vistas à compreensão do fenômeno em suas múltiplas dimensões. A conclusão da coleta foi determinada pelo critério de profundidade e suas interconexões, possibilitando abrangência da totalidade do problema investigado.

A abordagem dos participantes deu-se inicialmente pela análise dos prontuários dos usuários com transtornos mentais graves com histórico de atendimento no extinto hospital psiquiátrico e em tratamento na ocasião do estudo no CAPS II. Isso permitiu a identificação de seus familiares/cuidadores de referência e, assim, procedeu-se à abordagem pessoal de vinte familiares para responder às entrevistas e participar dos grupos focais.

O contato pessoal com os familiares foi realizado no CAPS II e nos domicílios, por ocasião da visita domiciliar. Nesse momento, foi entregue às famílias um cartão de agendamento, marcando a data dos encontros com a pesquisadora, os quais aconteceram em local, dia e horários pré-agendados e acordados com os familiares, com vistas à realização das entrevistas e dos grupos focais.

Os encontros para realização dos grupos focais aconteceram na Escola de Formação em Saúde da Família, por dispor de salas arejadas e com privacidade. Ao todo, foram realizados três grupos focais, sendo o primeiro com seis integrantes, o segundo, com oito e o terceiro, com seis familiares. Destaca-se que cada participante estava representando uma família. Os registros foram realizados por dois observadores, que anotaram as percepções e descrições, havendo também a gravação digital das falas do grupo. 
Os temas abordados nos encontros estavam relacionados às experiências e dificuldades vivenciadas no cuidado cotidiano da pessoa com transtorno mental, aos serviços oferecidos aos usuários e suas famílias pela rede de saúde mental e ao tipo de atendimento recebido.

A observação participante do cotidiano das famílias nos domicílios e nos dispositivos de atenção psicossocial foi realizada durante três meses. Os registros foram feitos no diário de campo. $\mathrm{O}$ referido método foi conduzido com o auxílio de um roteiro composto pelas temáticas potencializadoras de elucidação das questôes que delimitaram a pesquisa. A coleta iniciou após a aprovação do Comitê de Ética em Pesquisa (CEP) da Universidade Estadual Vale do Acaraú (UVA), com parecer no 90. 960, e ocorreu no período entre setembro a novembro de 2012.

$\mathrm{Na}$ análise do material empírico, para melhor entendimento das questões deste estudo, utilizou-se a fenomenologia hermenêutica de Ricoeur (1990). Buscou-se revelar o significado da experiência vivida pelos participantes da pesquisa, através da interpretação das narrativas transcritas nos textos obtido com as entrevistas, grupos focais e a observação participante.

A interpretação é vista como um processo que envolve etapas que se iniciam com a transcrição das entrevistas em texto, quando se reafirma a concepção de Ricoeur (1989) sobre distanciação (objetivação do texto), isto é, o deslocamento do problema do texto ao mundo que se abre. A seguir, tem-se a interpretação superficial, ou seja, a compreensão do significado do texto como um todo, por meio de leituras múltiplas e da identificação de temas principais.

O próximo passo foi a análise estrutural. Nessa etapa, o texto foi analisado por unidades de significado condensadas e agrupadas em grandes temas. $\mathrm{Na}$ última etapa, realizou-se a compreensão abrangente do texto, ou interpretação profunda, em que há identificação e revisão das unidades de significação de forma a serem analisadas a partir das pré-compreensóes do pesquisador. Esse processo interativo é representado em forma de espiral, pois relaciona as partes do texto com o todo e vice-versa.

Nesta pesquisa, buscou-se, portanto, entender os sentidos do texto, que levaram à compreensão das experiências das famílias de usuários com transtornos mentais nos dispositivos de atenção psicossocial. Com a elaboração dos temas, iniciou-se a análise das narrativas e sua interlocução com o estado da arte para construção de contrapontos e argumentações críticas sobre os múltiplos olhares. 
Buscou-se a compreensão das experiências singulares vivenciadas pelas famílias cuidadoras de usuários com transtornos mentais graves, operadas em RAISM. As temáticas elaboradas foram analisadas e interpretadas, tendo como ponto de partida as narrativas.

O primeiro tema constituiu-se de significados e sentidos sobre as dificuldades do cuidado em domicílio pelas famílias, destacando-se a adoção de uma situação de vigilância das famílias referente à supervisão de comportamentos problemáticos.

\section{Tema 1 - Dificuldades no tratamento domiciliar pelas famílias cuidadoras na atenção psicossocial}

Observou-se, nas entrevistas individuais, que as famílias supervisionam rotineiramente comportamentos problemáticos manifestados pelos seus familiares com transtornos mentais, evidenciando-se, assim, um cenário caracterizado pelas sobrecargas objetiva e subjetiva nos cuidadores. Dentre os comportamentos problemáticos, destacam-se: o discurso delirante e logorreico, o uso abusivo de cigarro e café, a prática de masturbação, a provocação de pessoas da comunidade, a colocação de apelidos nas pessoas de casa, e a ida a depósitos de lixo. Tais comportamentos alteram a dinâmica familiar, ocasionando conflitos e problemas de saúde para os cuidadores.

Não deixa ninguém dormir, conversa muita besteira à noite. Tem uma loucura por artistas de televisão, quer entrar na televisão para ser artista.

Conversa muito só dentro de casa, tem um caminhar, fica com as mãos como se fosse telefonando, eu fico também com uma desimpaciência [sic] com aquele movimento.

Um problema é não deixar o cigarro, isso me prejudica, me irrita, eu não durmo de noite espirrando. Toma muito café, é um vício grande.

Outra dificuldade é que coloca apelidos na família. Está com a mania de ficar intimando com o povo que passa na rua, o meu medo é esta pessoa não aguentar o palavreado besta e tentar invadir a casa.

Identificam-se, pela narrativa dos cuidadores, as complexidades inerentes ao papel que desempenham no cuidado de seus familiares com transtornos mentais. As dificuldades são transmitidas de maneira real e densa, explicitando a dramaticidade da situação vivenciada, sendo que a vigilância e a supervisão dos comportamentos manifestados são sentidas como necessidades a serem incorporadas cotidianamente. 
É surreal, difícil, doloroso e desafiador para as famílias lidar com conteúdos delirantes e de alucinação de pessoas com laços de afetividade e parentesco bastante próximos.

No que concerne à manifestação da sexualidade, como esta é expressa sem obediência às normas familiares e socialmente consensuadas, acarreta sentimentos de medo, vergonha e impotência nos cuidadores.

[...] todo dia fica se masturbando, quando eu saio de casa para resolver algo, muitas vezes eu fico preocupada com as pessoas em casa, agora nunca atacou ninguém [...]

Deve-se considerar que, independente de apresentarem transtorno mental, as pessoas com transtornos mentais são como as outras que possuem sexualidade, vontades e libido. É fato que, em virtude do transtorno mental, muitas poderão manifestar a busca pela satisfação dos desejos sexuais de maneira impulsiva, acrítica, gerando embaraços e desconforto.

As observações nos campos da atenção domiciliar propiciaram detectar que, para as famílias estudadas, é tarefa difícil e angustiante lidar com a sexualidade dos familiares com transtornos mentais. A atitude mais comum é a repressão e a negação da manifestação dos desejos sexuais. Em alguns casos específicos, detectou-se que os cuidadores recorrem à prática de solicitar um membro da família para levar os familiares com transtornos mentais para a prática de relação sexual com uma mulher "da vida" que realizava "programa" na comunidade.

A manifestação de comportamentos estranhos, atípicos e incoerentes pelos familiares com transtornos mentais é disparadora de criação de um campo fértil de preocupação e tensão constante para os cuidadores, acarretando alteraçõos marcantes no cotidiano do grupo familiar, que passa a se organizar tendo como referencial a pessoa com adoecimento mental.

[...] tem uma mania de andar pelo lixo procurando sapatos velhos. A gente compra uma chinela nova e passa uns três dias com a chinela, depois vai para o lixo e volta com chinela velha. Devido ele andar no lixo, pega doença nos pés, lá vai eu tratar [...].

Tal situação engessa o modo de gerenciar o dia a dia dos cuidadores, que passam a experienciar situações de vida extremamente reduzidas, empobrecidas, com desdobramentos e prejuízos importantes nas dimensões pessoal, familiar, comunitária e social.

O desempenho do papel de cuidador é explicitado pelos participantes da pesquisa como um aspecto desencadeador de repercussões importantes em sua saúde física e mental, consoante destacado na narrativa a seguir: 
[...] Eu já venho cansada de tanto lutar com doente mental. Passei um período de

seis anos tomando remédio, eu acho que eu também não queimo bem do juízo, não durmo de noite. É um aperreio muito grande na minha cabeça e no meu corpo.

Os achados da investigação encontram ressonância em outras investigações realizadas por diferentes estudiosos em cenários distintos. Os estudos de Greenberg et al. (1997), Martínez et al. (2000), Lauber et al. (2003) oferecem contribuições importantes, nas quais se identificam os comportamentos problemáticos como um dos principais fatores produtores de sobrecarga familiar.

As evidências da pesquisa desenvolvida por Barroso et al. (2007) detectaram a existência de sobrecargas objetiva e subjetiva vivenciadas pelas famílias cuidadoras. No âmbito da sobrecarga objetiva, os achados indicaram a supervisão do consumo excessivo de cigarros e de bebidas não alcoólicas, como café e refrigerantes. No tocante à sobrecarga subjetiva, o ato de supervisionar comportamentos vergonhosos dos familiares destacou-se como um dos itens mais incômodos para as famílias. Inclui-se também a relação de comportamentos problemáticos, envolvendo quadros de agitação, agressividade verbal, crise de nervos, fuga para a rua, requerimento constante de atenção, agressividade física, solilóquio (falar sozinho), quebra de objetos, recusa de medicação, nudez, problemas de sexualidade, dentre outros (BARROSO et al., 2007).

Cuidadores se sentem como se nunca estivessem totalmente tranquilos, devido às preocupaçôes que os acompanham no dia a dia, principalmente aquelas associadas à supervisão de comportamentos que o familiar adota ou poderá adotar, como tentativas de fuga ou suicídio (ALMEIDA et al., 2010).

As observações realizadas no campo da atenção psicossocial revelaram que a supervisão dos comportamentos problemáticos afeta a dinâmica familiar, acarretando problemas na saúde física e mental dos cuidadores. É patente o sofrimento mental expresso pelas famílias, também comunicado mediante formas diversas de somatizações.

Os trabalhadores da saúde precisam, de fato, conhecer as particularidades das dinâmicas e contextos de vida das famílias de indivíduos com transtornos mentais. Dessa maneira, poderão junto com cada grupo familiar construir projetos terapêuticos singulares, contribuindo de maneira mais efetiva no sentido de oferecer aos cuidadores possibilidades diferenciadas para lidarem com as situaçôes vivenciadas, aliviando sobrecargas e propiciando melhorias na qualidade de vida deles. 
Torna-se importante, portanto, que os serviços de saúde mental desenvolvam intervençōes domiciliares permanentes, visando à construção, junto às famílias, de estratégias para que estas lidem com os comportamentos problemáticos dos familiares com transtornos mentais.

\section{Tema 2 - Cuidado em saúde mental nos dispositivos de atenção psicossocial}

Mediante a realização dos grupos focais, percebeu-se, pelas narrativas dos familiares, a mudança de olhar sobre o cuidado em serviço substitutivo como estratégia de cuidado e construção de sujeitos. Nesse contexto, destaca-se a satisfação dos cuidadores quanto à atenção prestada pelo CAPS II.

Os cuidadores realizam avaliação positiva no que tange à atenção à saúde mental nos dias atuais. Destaca-se que essa atenção está centrada na oferta de serviços do CAPS. É unânime observar que esse dispositivo vem contribuindo para melhoria na qualidade de vida dos familiares com transtornos mentais e famílias, uma vez que classificam o atendimento como de qualidade e compromissado com o cuidado humanizado.

O tratamento hoje na saúde mental está muito bom. O CAPS veio para dar uma vida melhor para os pacientes e para as famílias; o atendimento é de qualidade, tem humanidade.

Os profissionais do CAPS têm atenção com a gente, fazem visita domiciliar. Tem as consultas com o enfermeiro, com o médico; quer dizer, é uma segurança e uma atenção boa esta da equipe da saúde mental.

Os cuidadores argumentaram ainda que o referido serviço se caracteriza como apoio relevante para as famílias, e evidenciaram sua contribuição no processo de aposentadoria. Outros aspectos destacados referiram-se à participação de pessoas com transtornos mentais nas atividades ofertadas pelo serviço e à diminuição do ciclo de internações.

O CAPS é um apoio importante para as famílias. Os dois CAPS têm me ajudado muito, já ajudou a aposentar uma filha; o CAPS AD a aposentar o meu outro filho.

Se não fica bom sobre o problema da doença é porque não tem que ficar, porque tratamento não falta, meu filho até faz questão de querer ir para o CAPS, ele gosta de participar das atividades, de fazer aquelas pinturas, as atividades físicas. Eu noto que junto com a medicação vai melhorando muito para ele. Nunca mais precisou internar, isto significa que o tratamento está dando certo. 
Segundo Silva e Braga (2009), dispositivos em saúde mental, como os CAPS, são de indiscutível importância para continuidade do tratamento, pois a participação de usuários nesses serviços potencializa a relação entre eles, a família e o trabalhador da saúde, oportunizando a intervenção em crise e minimizando os ciclos de internações e o afastamento do usuário de seu território, espaço de trocas afetivas e materiais.

Os estudos de Borba et al. (2011) demonstraram que as famílias cuidadoras consideram que, além da adesão ao tratamento medicamentoso, é importante a inclusão de outras atividades. As transformações ocorridas na forma de assistir a pessoa com transtorno mental, em decorrência do movimento da reforma psiquiátrica em curso no país, são percebidas pelos participantes da pesquisa como estratégias importantes para a humanização da assistência.

No entanto, além de se reconhecerem tais avanços, deve-se ter como imagem objetiva da atenção psicossocial o desenvolvimento de açôes de base territorial operadas por diversas categorias profissionais, e desse modo, ter especial atenção para a institucionalização das pessoas com transtorno mental no CAPS. A ênfase deve ser dada na capacidade da equipe de articular-se com o território, desenvolvendo relações com serviços comunitários, uma vez que o que se pretende "é uma rede de relações entre sujeitos, sujeitos que escutam e cuidam" (AMARANTE, 2007, p. 82).

Uma estratégia de inserção no território é a visita domiciliar realizada pelos profissionais do CAPS, valorizada pelos cuidadores. As observações no campo da atenção domiciliar demonstraram que os atendimentos em domicílio encontramse predominantemente centrados na questão medicamentosa, na prescrição de receitas e na sintomatologia apresentada pelo usuário com transtorno mental.

As visitas domiciliares precisam ser tomadas pela equipe do CAPS como uma atividade de cuidado direcionada também para as famílias cuidadoras. Devem ser desenvolvidas de maneira compartilhada com a equipe da ESF, focando não somente os aspectos prescritivos e biológicos, mas também a atenção psicossocial. Faz-se necessário reavaliar como as práticas estão sendo operadas. Assim, possibilitar-se-á o surgimento de novos caminhos para formas de cuidado, a serem construídas na relação estabelecida entre trabalhadores da saúde, usuários com transtornos mentais e seus familiares. 
As visitas domiciliares conjuntas, desenvolvidas em uma aliança formada pelo CAPS e a unidade de saúde da família, possibilitam a formação e qualificação dos vínculos entre os trabalhadores da saúde dos diferentes níveis de atenção e entre estes, os usuários com transtornos mentais e as famílias cuidadoras. Esse se configura como momento fértil para construção artesanal da corresponsabilização, na qual também os saberes, experiências e práticas podem ser compartilhados, desmistificando-se crenças e preconceitos arraigados que impedem a aproximação dos trabalhadores da ESF com os usuários com transtornos mentais.

Um dos objetivos das visitas domiciliares consiste em fortalecer o vínculo da equipe de saúde da família com a comunidade. Nelas, são realizados atendimentos conjuntos, para que ambas as equipes entendam a complexidade de cada grupo familiar e possam adentrar seus territórios subjetivos. Ouvir a história de cada membro, conhecer a dinâmica das relações estabelecidas naquela residência ou comunidade e perceber as dificuldades e potencialidades de cada um são atitudes que enriquecem a prática e ajudam a identificar possibilidades e agenciar recursos e serviços (DELFINI et al., 2009).

A realização de visitas domiciliares possibilita o conhecimento acerca dos usuários, de suas vivências, além de ser momento propício para o planejamento de estratégias terapêuticas, considerando-se a rotina da casa. O domicílio passa a funcionar como ambiente terapêutico, e o cuidado humanizado torna-se cada vez mais viável, propiciando a criação de vínculo entre a equipe e o usuário (SILVA et al., 2011).

Nesse sentido, o CAPS desponta como um dos principais dispositivos responsáveis pela articulação e fomento de construção de redes sociais. Assim, concorda-se com a posição de Almeida et al. (2004, p.118), quando defendem que:

Um CAPS não pode ser um "programa de auditório" para entreter, de modo medíocre, o vazio de vidas vazias, nem uma "instituição de capacitação técnica", para habilitar pobres a postos pobres do mercado de trabalho, apenas garantindo a empregabilidade de sobrevivência. O CAPS não pode ser apenas uma "clínica de psicose", mas um centro de inserção e mudança cultural, uma "usina de cidadania" articulando espaços fora dele, fazendo o cliente circular a cidade, não apartar-se dela.

Barros e Mângia (2007) enfatizam que as intervenções junto à população com transtornos mentais severos devem priorizar o fortalecimento das redes sociais, e não apenas o controle dos sintomas ou recaídas, ou ainda o simples desenvolvimento de habilidades. Nos dias atuais, um dos principais desafios 
para ampliação das possibilidades terapêuticas para as pessoas com transtornos

mentais graves reside na capacidade de realizar a integração entre diferentes segmentos sociais, serviços de saúde dos diversos níveis de atenção e articulação do cuidado no território comunitário e familiar do usuário.

As narrativas dos familiares, oriundas das entrevistas individuais e dos grupos focais, no concernente à assistência prestada pelo CAPS, evidenciaram, por outro lado, a necessidade de melhorias do cuidado nos moldes da atenção psicossocial.

$\mathrm{O}$ atendimento para as famílias acontece na hora do atendimento dos pacientes, as famílias estão muito distantes dos profissionais da saúde mental. Tem que ter integração maior entre família e equipe da saúde mental.

Deve ter mais visitas domiciliares para atender às famílias. Os profissionais precisam saber o que as famílias estão sentindo, quais são as dificuldades delas, pois só assim eles poderão ajudar as famílias que cuidam de pessoas com problemas mentais.

Observou-se o desejo das famílias de serem inseridas no cuidado em saúde mental, ou seja, não somente caracterizadas como corresponsáveis pelo tratamento de seus familiares com transtornos mentais, mas conotadas como pessoas que necessitavam de cuidados planejados e permanentes.

Santin e Klafke (2011) ressaltam que o trabalho com as famílias requer o estabelecimento de relações de cuidado com o cuidador, e não apenas a relação com o familiar no papel de familiar, isto é, uma relação que se volta para ouvir como essa pessoa se sente e como está sendo para ela cuidar e conviver em uma família em que há muito sofrimento psíquico, e não apenas trabalhar com questôes referentes ao auxílio da pessoa com transtorno mental, o que se deve fazer ou não fazer para que ela melhore.

As famílias participantes deste estudo forneceram outras pistas de como esse cuidado poderia ser ofertado e sugeriram a realização de grupos, que favoreceriam maior apoio às famílias cuidadoras, integrando-as à equipe de saúde mental.

Se tivesse grupos fixos para atendimento às famílias seria muito bom [...], nos grupos,
as famílias falavam as dificuldades, falavam não só de doença, mas de outros assun-
tos. [...]. É importante ter mais atenção com as famílias como se tem com os pacientes
[...], isso daria mais conforto, apoio, força para as famílias e unia mais os profissionais
com as famílias.

Há sentido na posição de Azevedo et al. (2009) quando defendem que se faz necessária a reformulação de estratégias que envolvam o familiar no acompanhamento e participação no tratamento da pessoa com adoecimento 
mental, reconhecendo-o como ator imprescindível e, portanto, capaz de redesenhar caminhos junto à equipe de saúde mental.

As famílias cuidadoras também chamam a atenção para a necessidade de regularização de medicamentos e disponibilização de transporte para os familiares com transtornos mentais participarem das atividades no CAPS.

Precisa regularizar o fornecimento dos medicamentos. Às vezes, falta um ou outro medicamento, e aí a gente precisa comprar porque não tem como deixar paciente mental sem medicamento. Se o remédio falta e o paciente não toma, ele descompensa e a crise chega sem pedir licença. O dinheiro é pouco para tudo, e para comprar os remédios fica tudo mais difícil.

Um problema que está acontecendo é com o transporte do CAPS, algumas vezes o carro não vem buscar em casa para levar para as atividades do CAPS. Tem que ter um transporte somente a serviço do CAPS para levar os pacientes que mais precisam para as atividades da semana, quando os pacientes participam das atividades, a gente vê que melhora o comportamento deles em casa.

As famílias cuidadoras argumentaram que a carência de medicamentos acarretava prejuízos como ônus financeiro para os cuidadores e a iminência de manifestação de um quadro de crise psicótica dos familiares com transtornos mentais.

As observações no campo da atenção psicossocial possibilitaram apreender que o fornecimento irregular de medicamentos durante determinado período estava associado à necessidade de maior agilidade no processo de licitação por parte do setor responsável do órgão público municipal, como também a questões envolvendo as empresas fabricantes dos medicamentos, as quais tiveram de lidar com problemas relativos à ausência de matéria-prima.

São muitas as repercussões oriundas da escassez de medicamentos. Dentre elas, os gastos financeiros dos cuidadores, que já têm de lidar com recursos limitados, e o fantasma da crise, que passa a fazer parte do cotidiano das famílias, produzindo angústia e tensões. Acrescente-se que muitas famílias, equivocadamente, fizeram a leitura de que a equipe do CAPS estava sonegando medicamentos. Isso gerou uma situação conflituosa e desagradável, na qual muitas famílias, em virtude dos sentimentos de medo e angústia que as invadiam, agrediram verbalmente a equipe de saúde mental, gerando tensões nas relações. A equipe da RAISM, por outro lado, sentiu-se também angustiada em presenciar as aflições vivenciadas pelas famílias, no tocante à possibilidade de recaída dos familiares com transtornos mentais, além de se perceber prejudicada no seu ato de cuidar. Acrescentam-se 
também linhas de tensões entre os trabalhadores e gestores e entre equipe da rede

e Unidades de Saúde da Família. Independentemente dos fatores causadores, a escassez de medicamentos ocasiona prejuízos de diferentes magnitudes, o que sinaliza para realização criteriosa de planejamento e de estoque de medicamentos.

Evidenciou-se ainda que a necessidade de transporte oferecido pelos CAPS se justifica pela gravidade da condição psiquiátrica de vários usuários assistidos, pelas dificuldades que apresentam de se deslocarem sozinhos, pela preocupação das famílias quando eles se deslocavam sozinhos, além dos reduzidos recursos financeiros para pagamento de serviços de transporte. Investigação realizada por Oliveira e Mendonça (2011) demonstrou que as famílias enfrentam problemas de acesso aos CAPS do município relacionados à distância geográfica, decorrentes de recursos financeiros insuficientes.

No decorrer das observações no campo da atenção psicossocial, identificou-se que havia automóvel convencional a serviço dos dois CAPS para realização de visitas domiciliares e de questôes burocráticas. Além disso, cada CAPS contava com os serviços de outro automóvel apropriado para transporte de usuários assistidos de maneira intensiva.

A irregularidade na prestação de serviços estava relacionada ao fato de que os automóveis eram cedidos pela Secretaria da Saúde, no período noturno e nos finais de semana, para o Juizado da Infância e da Adolescência, bem como para as unidades de saúde dos distritos. Dessa maneira, costumeiramente surgiam problemas mecânicos que demandavam o recolhimento dos automóveis para a oficina.

Esse fato repercute no projeto terapêutico dos usuários, pois muitos dependem do transporte para participar de atividades previstas em respectivos planos de cuidados. Há também repercussões na motivação da equipe, pois trabalhadores da saúde se queixavam que, em muitos casos, a situação interfere diretamente na adesão dos usuários ao tratamento. Sendo realizados encaminhamentos que envolvem os projetos terapêuticos, a assistência encontra-se prejudicada.

Outro desdobramento negativo do uso do transporte do CAPS pelo Juizado da Infância e da Adolescência é o de que o CAPS está sendo associado ao poder de polícia no imaginário de uma parcela da população. Assim, em alguns episódios, trabalhadores da saúde desse dispositivo, realizando visita domiciliar, foram ameaçados e convidados a se retirar dos bairros por indivíduos de algumas comunidades, oferecendo perigo para a integridade física e segurança da equipe. 
Observou-se, ainda, a necessidade de qualificação do acolhimento operado no equipamento CAPS. Os cuidadores alegaram que esperavam durante muito tempo na sala de recepção para serem atendidos em suas demandas, o que repercutia na organização da dinâmica familiar dos cuidadores. Quando o atendimento estava agendado para acontecer no turno da manhã, as famílias preparavam as refeições muito cedo, antes de se encaminharem para o CAPS, e também acabavam tendo de delegar atividades de casa para outros membros da família.

Deveria melhorar o acolhimento do CAPS, a gente espera muito na recepção no dia que tem consulta, atendimento. A gente chega muito cedo e já vem sair tarde.

Considerando-se os fatos relatados e a necessidade de proporcionar acolhimento consoante à humanização do cuidado, deve ser tarefa prioritária da equipe de saúde mental criar espaços permanentes com capacidade de oferecer escuta qualificada às famílias cuidadoras. As intervençôes precisam ser pensadas de maneira compartilhada, visando ajudar as famílias na superação de dificuldades. Isso implica repensar e reorganizar o cuidado operado no cotidiano nos dispositivos de atenção psicossocial.

Nesse cenário, é relevante o acolhimento que se traduz em uma proposta voltada para melhoria das relações dos serviços de saúde com os usuários. No encontro do usuário que procura o serviço espontaneamente com os profissionais de saúde, no qual há uma escuta, concretizam-se um processamento de sua demanda e uma busca de resolução, se possível (TESSER et al., 2010).

O vínculo apresenta estreita relação com a capacidade do outro de usufruir da condição de sujeito ativo nas decisões acerca da sua vida. É, portanto, o dispositivo que motiva os sujeitos (trabalhadores e usuários) ao encontro de suas potencialidades, pois favorece a reciprocidade de experiências e, assim, possibilita a construção de atos terapêuticos corresponsabilizados e coautorais (SANTOS, 2008). Nesse contexto, priorizam-se as descritas tecnologias leves, comunicacionais e relacionais, estratégias fundamentais no cuidar em saúde mental, operado na perspectiva da atenção psicossocial. Assim, Merhy (2007) enfatiza que os recursos das tecnologias leves permitem que os trabalhadores desloquem o modelo assistencial pautado no atendimento individual e curativo, no qual o foco da produção é o procedimento em si, para um modelo voltado para a produção de cuidados. 
Nos encontros realizados nos campos da atenção domiciliar e psicossocial, constatou-se que, de fato, as famílias encontravam-se distantes do olhar e do cuidado prioritário da equipe dos dispositivos da RAISM. Eram atendidas, predominantemente, no momento da assistência realizada aos familiares com transtornos mentais.

Observou-se que as visitas domiciliares eram direcionadas para os familiares com transtornos mentais, os quais, em virtude do comprometimento, do quadro mental ou da situação física, encontravam-se impossibilitados de receber atendimento nos dispositivos da RAISM. Nessas atividades, predominavam a terapêutica medicamentosa, os procedimentos de exames, a prescrição de receitas e a observância acerca da sintomatologia apresentada. Não se identificaram açōes que objetivassem estimular as famílias a participarem ativamente do projeto terapêutico dos familiares, nem direcionadas prioritariamente para cuidar dos cuidadores.

\section{Consideraçōes finais}

Esta pesquisa foi elaborada com base em questionamentos acerca das experiências de familiares de usuários com transtornos mentais atendidos nos dispositivos de atenção psicossocial. Em face do objetivo e do componente crítico e interpretativo do estudo, no universo da convivência da família com a pessoa com transtorno mental, há dificuldades expressas num contexto de necessidade de vigilância de comportamentos problemáticos, complexos e desgastantes para as famílias, que vivenciam sobrecargas objetivas e subjetivas.

No concernente ao cuidado operado nos dispositivos de atenção psicossocial, percebeu-se, pelas narrativas, a satisfação das famílias cuidadoras com a atenção prestada pelo CAPS II. Apesar da necessidade de melhorias como sua inserção no cuidado em saúde mental, qualificação do acolhimento, regularização da escassez de medicamentos e garantia de transporte para os usuários assistidos, esse serviço é visto como o único espaço em que os usuários e seus familiares encontram apoio, não sendo referidos outros dispositivos da rede assistencial.

Questiona-se a ênfase dada às atividades desenvolvidas no CAPS II, uma vez que a atenção psicossocial deve operar ações de base territorial para além do CAPS, com diversos saberes e práticas da equipe, sendo capaz de articular-se com o território e a rede de serviços assistenciais e comunitários. 
A inserção na comunidade favorece a aproximação com as famílias, valorizando seus saberes e experiências no cuidado em saúde mental, efetivando o cuidado psicossocial corresponsável, envolvendo equipe de saúde, usuários e seus familiares, em que todos exercitem o papel de protagonistas, colaborando fundamentalmente para criação de novas formas de subjetivação do papel das famílias cuidadoras.

Acrescenta-se que os serviços ancorados na perspectiva da atenção psicossocial devem oferecer às famílias assistidas cuidado planejado e permanente. A equipe de saúde mental precisar criar espaços com capacidade de oferecer escuta qualificada aos cuidadores, oferecendo suporte terapêutico e estimulando seu protagonismo, em congruência com uma atenção em saúde mental compromissada com o cuidado e a emancipação cidadã. ${ }^{1}$

\section{Referências}

ALMEIDA, M.M. et al. A sobrecarga de cuidadores de pacientes com esquizofrenia. Rev Psiquiatr Rio Gd Sul., v.32, n.3, p.73-79, 2010.

ALMEIDA, M.M. et al. Oficinas em saúde mental: relato de experiências em Quixadá e Sobral. In: COSTA, C. M; FIGUEIREDO, A. C. (Orgs.). Oficinas terapêuticas em saúde mental. Sujeito, produção e cidadania. Rio de Janeiro: Contracapa livraria, 2004. p.117-133 (Coleções Ipub).

AMARANTE, P. Saúde mental e atenção psicossocial. Rio de Janeiro: Fiocruz, 2007.

AZEVEDO M. et al. Percepções de familiares sobre o portador de sofrimento psíquico institucionalizado. Esc Anna Nery, v.13, n.3, p.485-491, 2009.

BARROS, J.O.; MÂNGIA, E.F. Rede social e atenção às pessoas com transtornos mentais: novo desafio para os serviços de saúde mental. Rev Ter Ocup Univ., v.18, n.3, p.135-142, 2007. BARROSO, S.M.; BANDEIRA, M.; NASCIMENTO, E. Sobrecarga de familiares de pacientes psiquiátricos atendidos na rede pública de Belo Horizonte. Rev Psiquiatr Clín., v.34, p.270-27, 2007.

BORBA, L.O. et al. A família e o portador de transtorno mental: dinâmica e sua relação familiar. Rev Esc Enferm USP., v.45, n.2, p.442-449, 2011.

BRASIL. Ministério da Saúde. Relatório Final da IV Conferência Nacional de Saúde Mental - Intersetorial, 27 de junho a 1 de julho de 2010. Brasília: Conselho Nacional de Saúde/ Ministério da Saúde, 2010, 210 p.

DELFINI, P.S.S. et al. Parceria entre CAPS e PSF: o desafio da construção de um novo saber. Ciênc Saúde Coletiva, v.14, supl.1, p.1483-1492, 2009. 
DIMENSTEIN, M. et al. Estratégia da Atenção Psicossocial e participacão da família no cuidado em saúde mental. Physis: Revista de Saúde Coletiva. Rio de Janeiro, v.20, n.4, p.1209-1226, 2010.

GREENBERG, J.S.; KIM, H.W.; GREENLEY, J.R. Factors associated with subjective burden in siblings of adults with severe metal illness. Am J Orthopsychiatry, v.67, n.2, p.231-241, 1997. INSTITUTO BRASILEIRO DE GEOGRAFIA E ESTATÍSTICA. Censo populacional 2011. Disponível em: //www.ibge.gov.br. Acesso em: 29 abr. 2011.

JORGE, M.S.B; PINTO, A.G.A. Adoecimento mental e a família: representações e subjetividades. In TRAD, L.A.B. (Org.). Família Contemporânea e Saúde: significados, práticas e políticas públicas. Rio de Janeiro: FIOCRUZ, 2010. p.335-379.

KOGA, M. Convivência com a pessoa esquizofrênica: sobrecarga familiar. 1997. Dissertação (Mestrado em Enfermagem) - Universidade de São Paulo, Ribeirão Preto, 1997.

LAUBER, C. et al. Determinants of burden in caregivers of patients with exacerbating schizophrenia. European Psychiatry, v.18, p.285-289, 2003.

MARTÍNEZ, A. et al. El enfermo esquizofrénico y sus familias immersos en un cambio profundo. ANALES Sis, v.23, n.1, p. 11-122, 2000.

MERHY, E. E. Saúde: a cartografia do trabalho vivo. 3. ed. São Paulo: Hucitec, 2007.

MORENO, V. Familiares de portadores de transtorno mental: vivenciando o cuidado em um centro de atenção psicossocial. Rev Esc Enferm USP, v.43, n.3, p.566-572, 2009.

NAVARINI, V.; HIRDES, A. A família do portador de transtorno mental: identificando recursos adaptativos. Texto Contexto Enferm., v.17, n.4, p.680-688, 2008.

NÓBREGA, S.A.; CORIOLANO, M.W.L. Experiência de familiares no cuidado em saúde mental. Saude \& Transf Soc., v.1, n.2, p.101-107, 2011.

OLIVEIRA, E. B.; MENDONÇA, J. L. S. Dificuldades enfrentadas pela família no acolhimento do paciente com transtorno mental após a alta hospitalar. Rev Enferm UERJ, v.19, n.2, p.198-203, 2011.

PERGORARO, R.F.; CALDANA, R.H.L. Sofrimento psíquico em familiares de usuários de um Centro de Atenção Psicossocial (CAPS). Interface - Comun Saude Educ., v.12, n.25, p.295-307, 2008.

PIMENTA, E.S.; ROMAGNOLI, R.C. A relação com as familias no tratamento de transtorno mental realizado no Centro de Atenção Psicossocial. São João Del-Rei: Pesquisa e Práticas Psicossociais, 2008.

RICOEUR, P. Interpretação e ideologias. Rio de Janeiro: Francisco Alves, 1990.

ROSA, L.C.S. A inclusão da família nos projetos terapêuticos dos serviços de saúde mental. Psicologia em Revista, v.11, n.18, p.205-218, 2005. 
SANTANA, L.O.P.L.S. O entardecer no farol: um estudo etnográfico sobre a percepção da saúde entre pessoas idosas. Fortaleza, 2004. Dissertação (Mestrado) - Centro de Ciências da Saúde, Universidade Estadual do Ceará.

SANTIN, G.; KLAFKE, T.E. A família e o cuidado em saúde mental. Barbaroi, n.34, p.146-160, 2011.

SANTOS, A.M. et al. Vínculo e autonomia na prática de saúde bucal no Programa Saúde da Família. Rev Saúde Pública, v.42, n.3, p.464-470, 2008.

SILVA, C.S; DALMOLIN, B. O cotidiano familiar de quem vivencia o transtorno mental. Saúde em debate, v.34, n.86. p.549-558, 2010.

SILVA, M.; BRAGA, B. Reforma, responsabilidades e redes: sobre o cuidado em saúde mental. Cienc Saúde Coletiva., v.14, p.149-158, 2009.

SILVA, R.C.B. Esquizofrenia: uma revisão. Psicol USP., v.17, n.4, p.263-285, 2006.

SILVA, C.M.C. et al. Visita domiciliar na atenção à saúde mental. Cienc Enferm, v.17, n.3, p.125-136, 2011.

TESSER, C.D. et al. Acolhimento e (des) medicalização social: um desafio para as equipes de saúde da família. Ciênc Saúde Coletiva, v.15, supl.3, p.3615-3624, 2010.

VASCONCELOS, M.G.F. Projeto terapêutico como dispositivo de cuidado na rede de atenção à saúde mental e sua (des)articulação com a estratégia saúde as família (ESF). Dissertação (Mestrado Acadêmico em Saúde Pública) - Universidade Estadual do Ceará, Fortaleza, 2011.

\section{Nota}

${ }^{1}$ M.M. M. de Barros e M.S. Bessa Jorge trabalharam nas etapas de concepção, interpretação dos dados e aprovação final da versão a ser publicada do artigo. M.G.F. Vasconcelos realizou revisão crítica relevante do conteúdo intelectual e aprovação final da versão a ser publicada do artigo. 


\section{Abstract}

Experience of families with members assisted at the psychosocial care facilities

Qualitative research conducted in Northeast Brazil, from September to November 2012, seeking to understand the experiences of families with users attended in psychosocial care units. Data collection used structured interviews, focus groups and participant observation. Participants were twenty families caregivers of adult users with severe mental disorders, with a history of psychiatric care in extinct hospital and being treated, at the time of the study, at a psychosocial care unit. In the empirical analysis, we used the phenomenological hermeneutics of Ricoeur. Families faced difficulties in domestic care, especially the situation of surveillance of problematic behaviors of family members with mental disorders. Families were satisfied with the care provided by the unit; however, they highlighted the need for improvements there, by their insertion in mental health care, qualification of host operating the service, regularization of the shortage of medicines and ensuring transportation for family members with mental disorders being cared for.

> Key words: families; experience; psychiatric reform. 